\title{
Shear Performance of RC Beams with Externally Bonded FRP Wraps
}

\author{
K.Anitha, R.Venkatakrishnaiah, T.P.Meikandaan, M.Hemapriya
}

\begin{abstract}
This examination demonstrates the shear execution of invigorated bond (RC) shafts fortified with remotely braced carbon fiber reinforced polymer (CFRP) wraps and Glass fiber sustained polymer (GFRP). The test program involved testing six, full-scale, RC columns. The components investigated in this investigation concentrate included steel stirrups. As a segment of the examination program, the test concentrate investigated the reasonability of CFRP and GFRP fortress in improving the shear furthest reaches of $\mathrm{RC}$ bars, and for bars with rectangular fragment. The test outcomes demonstrated that the responsibility of remotely braced CFRP and GFRP to as far as possible is basic and subordinate upon the variable inspected. Where they are finally taken a gander at and investigated that the going with which is more astute to be used in the field of advancement
\end{abstract}

Keywords: CFRP, GFRP

\section{INTRODUCTION}

This examination demonstrates the shear execution of sustained bond (RC) shafts strengthened with remotely braced carbon fiber reinforced polymer (CFRP) wraps and Glass fiber invigorated polymer (GFRP) [1],[3],[5]. The test program involved testing six, full-scale, RC columns. The elements investigated in this investigation concentrate included steel stirrups. As a part of the examination program, the test concentrate investigated the suitability of CFRP and GFRP stronghold in improving the shear furthest reaches of RC bars, and for bars with rectangular portion[2 ],[4],[6]. The test outcomes demonstrated that the responsibility of remotely braced CFRP and GFRP to as far as possible is basic and subordinate upon the variable inspected. Where they are finally taken a gander at and examined that the going with which is more astute to be used in the field of advancement.. In this Fortified bond is a composite material where strong's low versatility and adaptability are checked by the fuse of fortress having higher unbending nature or flexibility[7],[9], [11]. The help is generally, anyway not by any stretch of the imagination, steel bracing bars and is

Revised Manuscript Received on July 22, 2019

K.Anitha, Assistant Professor, Department of Civil Engineering, Bharath Institute Of Education And Research, Chennai , Tamil Nadu. E-Mail: anithakrish26@yahoo.co.in

Dr.R.Venkatakrishnaiah, Associate Professor, Department of Civil Engineering, Bharath Institute Of Education And Research, Chennai, Tamil Nadu.E-Mail: venkatapec@gmail.com

T.P.Meikandaan, Associate Professor, Department of Civil Engineering, Bharath Institute Of Education And Research, Chennai , Tamil Nadu. E-Mail: ganga_meik@yahoo.co.in

M.Hemapriya, Assistant Professor, Department of Civil Engineering Bharath Institute Of Education And Research, Chennai , Tamil Nadu. E-Mail: meihemapriya@gmail.com ordinarily embedded latently in the strong before the strong sets Strengthening and rebuilding of existing sustained strong structures is transforming into a huge issue in conditions, for instance, demand in the extension of organization weight levels, fix due to corruption of a section, plan/improvement blemishes, and response to requirements of as of late made structure rules[8],[10] ,[12]. Carbon fiber invigorated polymer sheets continue demonstrating unbelievable. These materials are incredible for outer reinforcing due to their high elasticity, light weight, protection from erosion, prevalent sturdiness, and practical establishment process. Shear disappointment of RC pillars, brought about by their fragile nature, has been distinguished as the most lamentable disappointment mode; it happens with no guidance ahead of time of trouble[13], [15], [17]. Shear inadequacy may happen because of numerous variables, for example, lacking shear fortification or decrease in steel territory because of erosion, expanded administration burden, and development mistakes. Likewise, there is a dire need to redesign shear obstruction of more established RC structures to satisfy current seismic plan guidelines in areas with high seismicity.

\section{OBJECTIVE}

Explore the shear execution and method of disappointment of RC pillars in the wake of fortifying with remotely fortified FRP sheets[14],[ 16], [18]. Look at the viability of FRP fortification in upgrading the shear limit of RC bars in negative and positive minute locales, just as RC bars with rectangular area. Address the factors influencing the shear limit of fortified pillars such assteel stirrups, shear length to profundity proportion, FRP sum and appropriation, reinforced surface, fiber direction, and end grapple. To satisfy these objectives, twenty-seven full-scale, RC pillars configuration to flop in shear, were built and reinforced with various FRP setups and full investigation was done.

\section{METHODOLOGY}

\section{A. Aggregate}

I. Total are the major and significant constituents of cement. They structure the entire collection of concrete as it involves 70 to $80 \%$ of the volume of cement. In spite of the fact that totals were considered as dormant material before which have been observed as of late to be artificially dynamic somewhat. [19],[21],[23]. Bond is the main industrial 
facility made segment where considered as total (both fine and coarse) and water accessible materials. Cement can be considered as a two stage is associated with concrete which has been examined in the past segment. Presently the total stage is examined Aggregate might be named CoarseAggregate and Fine Aggregate

\section{B. Coarse Aggregate}

The Coarse total is free from clayey issue, residue and natural contaminations and so forth., the coarse total is likewise tried for explicit gravity and it is 2.82 , fineness modulus of coarse total is 4.07. [20],[ 22], [24]. Total of typical size $20 \mathrm{~mm}$ downsized $60 \%$ passed on $20.0 \mathrm{~mm}$ sifter and staying $40 \%$ is taken from the strainer $10.0 \mathrm{~mm}$ (passing) and $4.75 \mathrm{~mm}$ (held) is utilized in the exploratory work, which is adequate as per IS:383-1970

\section{C.Fine aggregate}

Fine total is sand which is normally acquired from waterways or lakes. Now and again shoreline sand is additionally utilized. In spots where sand isn't accessible or a huge amount of sand is to be utilized squashed stone residue is utilized. The fineness modulus of sand ought to associate with 2 to 3.2

\section{Fibre Reniforced Polymer}

"Fiberglass reinforced plastics" or FRPs use material assessment glass fibers. These material strands are not equivalent to various sorts of glass fibers used to deliberately trap air, for securing applications. Material glass fibers begin as moving mixes of $\mathrm{SiO} 2, \mathrm{Al} 2 \mathrm{O} 3, \mathrm{~B} 2 \mathrm{O} 3, \mathrm{CaO}$, or $\mathrm{MgO}$ in powder structure. These mixes are then warmed through direct condensing to temperatures around 1300 degrees Celsius, after which fails miserably are used to remove filaments of glass fiber in estimation reaching out from 9 to $17 \mu \mathrm{m}[25],[27],[29]$.

These strands are then damage into greater strings and spun onto bobbins for transportation and further planning. Glass fiber is by a wide edge the most standard plans to reinforce plastic and therefore acknowledges a wealth of age shapes, some of which are pertinent to aramid and carbon fibers additionally inferable from their regular stringy attributes.

\section{E. Carbon Fiber Reinforced Polymer}

A Fiber Reinforced Polymer (CFRP) composite is described as a polymer (plastic) cross section, either thermoset or thermoplastic, that is fortified (solidified) with a fiber or other strengthening material with a sufficient point extent (length to thickness) to give an observable bracing limit in at any rate one course. FRP composites are not equivalent to standard advancement materials, for instance, steel or Aluminum. FRP composites are anisotropic (properties clear toward the associated weight) while steel or aluminum is isotropic (uniform properties all over, self-sufficient of associated load) [26],[28],[30]. Thusly, FRP composite properties are directional, inferring that the best mechanical properties are toward the fiber placementThere are three wide divisions into which employments of CFRP in basic planning can be requested: applications for new advancement, fix and reclamation applications, and building applications. CFRPs have by and large been used by basic pros in the arrangement of new constructionFor assistant applications, CFRP is primarily used in two zones. The primary region incorporates the use of CFRP sheets/plates which is to invigorate in a general sense lacking helper people with outside utilization of CFRP. Retrofitting with concrete fortified CFRP has been developed far and wide as a convincing procedure suitable to various sorts of bond helper parts, for instance, sections, columns, pieces and dividers. The other application, usage of CFRP bars as opposed to steel bracing bars or pre-concentrating on strands in strong structure.

\section{RESULTS \\ A. TEST ON HARDENED CONCRETE}

To decide the compressive quality of solidified cement, testicles are directed on 3D shape and the outcomes are organized in table 1.

\begin{tabular}{|c|c|}
\hline \multicolumn{2}{|c|}{ Compressive strength, $\mathbf{N} / \mathbf{m m}^{2}$} \\
\hline 7 DAYS & 28 DAYS \\
\hline 18.17 & 27.76 \\
\hline
\end{tabular}

Splite strain testicles are led on solid chambers to decide the elasticity and the outcomes are arranged in table 2

\begin{tabular}{|c|c|}
\hline \multicolumn{2}{|c|}{ Tensile strength, $\mathrm{N} / \mathrm{mm}^{2}$} \\
\hline 7 DAYS & 28 DAYS \\
\hline 2.80 & 3.26 \\
\hline
\end{tabular}

\section{B. TEST ON CONCRETE BEAM}

To decide the quality of the solid bars with and without carbon fiber strengthened polymer are tried in stacking edge instrument, the outcomes are as per the following[31],[33] 


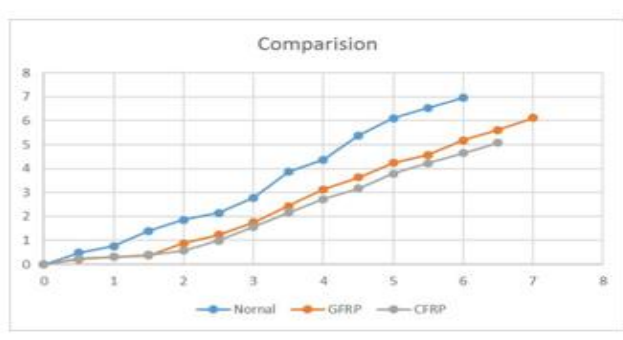

\section{CONCLUSION}

The tests results portrayed in this examination showed that the fortifying procedure dependent on remotely fortified CFRP composites can be utilized to expand essentially shear limit of RC pillars, with effectiveness that changes relying upon the test factors. In view of the trial results, diagnostic examinations, and talks, the fundamental ends. Remotely fortified CFRP fortification can be utilized to upgrade the shear limit of RC pillars. The FRP reinforcing strategy is pertinent and can build the shear limit of rectangular bars. Here after the testing of pillars the estimations of GFRP, CFRP qualities are contrasted all together with discover the quality which can acquire greatest. Lastly reasoned that GFRP give the high while contrasting with the CFRP and its better to incline toward CFRP [32],[34]

\section{REFERENCES}

1. Iyappan L., Dayakar P., Identification of landslide prone zone for coonoortalukusing spatial technology, International Journal of Applied Engineering Research,V-9,I-22,PP-5724-5732,Y-2014.

2. Kumar J., Sathish Kumar K., Dayakar P.,Effect of microsilica on high strength concrete, International Journal of Applied Engineering Research,V-9,I-22,PP-5427-5432,Y-2014.

3. Dayakar P., Vijay Ruthrapathi G., Prakesh J., Management of bio-medical waste, International Journal of Applied Engineering Research,V-9,I-22,PP-5518-5526,Y-2014.

4. Swaminathan N., Dayakar P., Resource optimization in construction project, International Journal of Applied Engineering Research,V-9,I-22,PP-5546-5551,Y-2014.

5. Venkat Raman K., Dayakar P., Raju K.V.B.,An experimental study on effect of cone diameters in penetration test on sandy soil, International Journal of Civil Engineering and Technology,V-8,I-8,PP-1581-1588,Y-2017.

6. Saritha B., Chockalingam M.P.,Photodradation of malachite green DYE using TIO2/activated carbon composite,International Journal of Civil Engineering and Technology,V-8,I-8,PP-156-163,Y-2017

7. Shendge R.B., Chockalingam M.P., Saritha B., Ambica A.,Swat modelling for sediment yield: A case study of Ujjani reservoir in Maharashtra, India,International Journal of Civil Engineering and Technology,V-9,I-1,PP-245-252,Y-2018

8. Chockalingam M.P., Balamurgan V.,Modernisation of an existing urban road-sector in Chennai, a case study report,International Journal of Civil Engineering and Technology,V-8,I-8,PP-1457-1467,Y-2017

9. Saritha B., Chockalingam M.P.,Adsorption study on removal of basic dye by modified coconut shell adsorbent, International Journal of Civil Engineering and Technology,V-8,I-8,PP-1370-1374,Y-2017

10. Saritha B., Chockalingam M.P.,Adsorptive removal of heavy metal chromium from aqueous medium using modified natural adsorbent,International Journal of Civil Engineering and Technology,V-8,I-8,PP-1382-1387,Y-2017

11. Chockalingam M.P., Palanivelraja S.,Retrospective analysis of a theoretical model used for forecasting future air quality near the north Chennai thermal power plant,International Journal of Civil Engineering and Technology,V-8,I-8,PP-1457-1467,Y-2017

12. Saritha B., Chockalingam M.P.,Photodegradation of methylene blue dye in aqueous medium by $\mathrm{Fe}-\mathrm{AC} / \mathrm{TiO} 2$ Composite,Nature Environment and Pollution Technology,V-17,I-4,PP-1259-1265,Y-2018

13. Shendge R.B., Chockalingam M.P., Kaviya B., Ambica A.,Estimates of potential evapotranspiration rates by three methods in upper Bhima Basin,
In Maharashtra, India,International Journal of Civil Engineering and Technology,V-9,I-2,PP-475-480,Y-2018

14. Shendge R.B., Chockalingam M.P.,The soil and water assessment tool for Ujjani Reservoir,International Journal of Mechanical Engineering and Technology, V-9,I-2,PP-354-359,Y-2018

15. Shendge R.B., Chockalingam M.P.,A review on soil and water assessment tool,International Journal of Mechanical Engineering and Technology,V-9,I-2,PP-347-353,Y-2018

16. Sachithanandam P., Meikandaan T.P., Srividya T.,Steel framed multi storey residential building analysis and design,International Journal of Applied Engineering Research,V-9,I-22,PP-5527-5529,Y-2014

17. Meikandaan T.P., Ramachandra Murthy A.,Study of damaged RC beams repaired by bonding of CFRP laminates,International Journal of Civil Engineering and Technology,V-8,I-2,PP-470-486,Y-2017

18. Meikandaan T.P., Ramachandra Murthy A.,Retrofittng of reinforced concrete beams using GFRP overlays,International Journal of Civil Engineering and Technology,V-8,I-2,PP-423-439,Y-2017

19. Meikandaan T.P., Ramachandra Murthy A.,Flexural behaviour of RC beam wrapped with GFRP sheets,International Journal of Civil Engineering and Technology,V-8,I-2,PP-452-469,Y-2017

20. Meikandaan T.P., Murthy A.R.,Experimental study on strengthening of rc beams using glass Fiber,International Journal of Civil Engineering and Technology,V-9,I-11,PP-959-965,Y-2018

21. Meikandaan T.P., Hemapriya M.,Use of glass FRP sheets as external flexural reinforcement in RCC Beam,International Journal of Civil Engineering and Technology,V-8,I-8,PP-1485-1501,Y-2017

22. Saraswathy R., Saritha B.,Planning of integrated satellite township at Thirumazhisai,International Journal of Applied Engineering Research,V-9,I-22,PP-5558-5560,Y-2014

23. Saritha B., Ilayaraja K., Eqyaabal Z.,Geo textiles and geo synthetics for soil reinforcement,International Journal of Applied Engineering Research,V-9,I-22,PP-5533-5536,Y-2014

24. Ambica A., Saritha B., Changring G., Singh N B., Rajen M., Salman Md.,Analysis of groundwater quality in and around Tambaram taluk, Kancheepuram district,International Journal of Civil Engineering and Technology,V-8,I-8,PP-1362-1369,Y-2017

25. Arunya A., Sarayu K., Ramachandra Murthy A., Iyer N.R.,Enhancement of durability properties of bioconcrete incorporated with nano silica,International Journal of Civil Engineering and Technology,V-8,I-8,PP-1388-1394,Y-2017

26. Ilayaraja K., Krishnamurthy R.R., Jayaprakash M., Velmurugan P.M., Muthuraj S.,Characterization of the 26 December 2004 tsunami deposits in Andaman Islands (Bay of Bengal, India),Environmental Earth Sciences,V-66,I-8,PP-2459-2476,Y-2012

27. Ilayaraja K.,Morphometric parameters of micro watershed in Paravanar sub-basin, Cuddalore District,International Journal of Civil Engineering and Technology,V-8,I-8,PP-1444-1449,Y-2017

28. Ilayaraja K., Singh R.K., Rana N., Chauhan R., Sutradhar N.,Site suitability assessment for residential areas in south Chennai region using remote sensing and GIS techniques,International Journal of Civil Engineering and Technology,V-8,I-8,PP-1468-1475,Y-2017

29. Ilayaraja K., Reza W., Kumar V., Paul S., Chowdhary R.,Estimation of land surface temperature of Chennai metropolitan area using Landsat images,International Journal of Civil Engineering and Technology,V-8,I-8,PP-1450-1456,Y-2017

30. Chitra R.,Experimental study on beam using steel fiber and latex,International Journal of Civil Engineering and Technology,V-8,I-8,PP-1395-1403,Y-2017

31. Chitra R.,Analysis of traffic and management at Kovilambakkam intersection,International Journal of Civil Engineering and Technology,V-8,I-8,PP-1433-1443,Y-2017

32. Aswathy M.,Experimental study on light weight foamed concrete,International Journal of Civil Engineering and Technology,V-8,I-8,PP-1404-1412,Y-2017

33. Aswathy M.,Wastewater treatment using constructed wetland with water lettuce (Eichornia Crasipies),International Journal of Civil Engineering and Technology,V-8,I-8,PP-1413-1421,Y-2017

34. Kiruthiga K., Anandh K.S., Gunasekaran K, Assessment of influencing factors on improving effectiveness and productivity of construction engineers, 2015, International Journal of Applied Engineering Research, V - 10,I -17,p -13849-13854. 


\section{AUTHORS PROFILE}

K.Anitha, Assistant Professor, Department of Civil Engineering, Bharath Institute of Higher Education and Research, Chennai, India

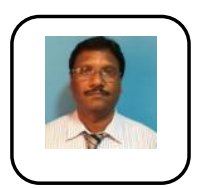

Dr.R.Venkatakrishnaiah Associate Professor, Department of Civil Engineering, Bharath Institute of Higher Education and Research, Chennai, India

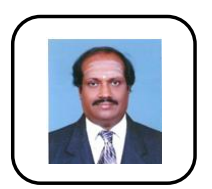

T.P.Meikandaan, Associate Professor, Department of Civil Engineering, Bharath Institute of Higher Education and Research, Chennai, India

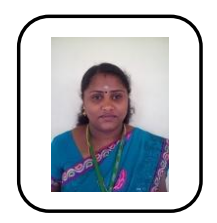

M.Hemapriya, Assistant Professor, Department of Civil Engineering, Bharath Institute of Higher Education and Research, Chennai, India 